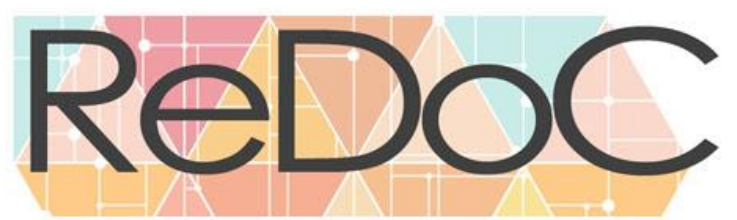

Revista Docência e Cibercultura

\title{
A CONCESSÃO DE REFÚGIO À PESSOAS LGBT
}

\author{
REFUGEES FOR LGBT PEOPLE
}

\section{LA CONCESIÓN DE REFUGIO A PERSONAS LGBT}

Allan Vieira Santos ${ }^{1}$

RESUMO: Além do banimento social, vivenciado em várias sociedades ao longo do globo, cidadãos LGBT enfrentam problemas que incluem a legislação e a prisão em vários países, além de serem objetos de contínuos ataques. O infortúnio é no sentido de que, após saírem de seus países, algumas perseguições ainda podem persistir. Isto se dá na medida em que solicitantes de refúgio com condições sexuais e expressões de gênero dissidentes apresentam fragilidades distintas. Apesar de subsistirem avanços nas políticas que implementaram o refúgio, inclusive com a adoção da Declaração sobre Direitos Humanos, Orientação Sexual e Identidade de Gênero ${ }^{2}$, a promoção de direitos de igualdade para com a população LGBT ainda caminha a passos módicos. Este estudo busca analisar como a percepção de vivências pessoais de perseguição com vistas a demonstrar pertencer a um grupo social específico pode reforçar estereótipos de sexualidade e gênero que acabam por marginalizar e prejudicar a proteção a pessoas LGBT, reforçando aspectos de uma perseguição que pode estar se deslocando do país de origem para o país de acolhimento.

PALAVRAS-CHAVE: Refúgio; Teoria Queer; Direitos Humanos; Perseguição; Migração.

ABSTRACT: In addition to the social ban, experienced in various societies across the globe, LGBT citizens face problems that include legislation and imprisonment in various countries, as well as being the object of continuous attacks. The misfortune is in the sense that, after leaving their countries, some persecution may still persist. This is so insofar as refugee seekers with sexual conditions and dissenting gender expressions present distinct weaknesses. Despite

Submetido em: 10/03/2019

Aceito em: 08/04/2019

Publicado em: 01/06/2019

${ }^{1}$ Mestranda em Ciências Jurídicas e Sociais pela Universidade Federal Fluminense (UFF), Especialista em Direitos Humanos, Democracia e Cultura pela Universidade Federal de Goiás (UFG) e Bacharel em Direito pela Escola de Direito de Brasília do Instituto Brasiliense de Direito Público (EDB/IDP).

${ }^{2}$ United Nations Human Rights - Office Of The High Commissioner. Born free and Equal - Sexual Orientation and Gender Identity in International Human Rights Law. New York and Geneva, 2012. Disponível em: < https://www.ohchr.org/Documents/Publications/BornFreeAndEqualLowRes.pdf>. Acesso em 12 de junho de 2018. 


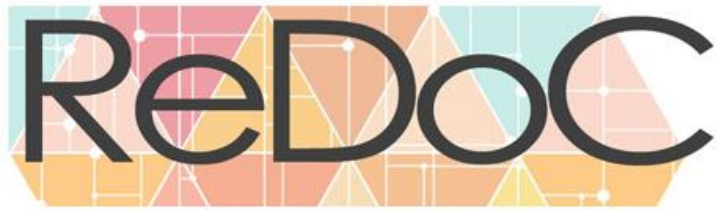

\section{Revista Docência e Cibercultura}

advances in the policies that have implemented the refuge, including the adoption of the Declaration on Human Rights, Sexual Orientation and Gender Identity ${ }^{3}$, the promotion of equal rights for the LGBT population is still taking modest steps. This study seeks to analyze how the perception of personal experiences of persecution with a view to demonstrating belonging to a specific social group can reinforce stereotypes of sexuality and gender that end up marginalizing and harming the protection of LGBT people, reinforcing aspects of a persecution that may be moving from the country of origin to the host country.

KEY WORDS: Refuge; Queer Theory; Human rights; Persecution; Migration.

RESUMEN: Además de la prohibición social, vivida en varias sociedades a lo largo del globo, los ciudadanos LGBT enfrentan problemas que incluyen la legislación y la detención en varios países, además de ser objeto de continuos ataques. La desgracia es que, después de salir de sus países, algunas persecuciones todavía pueden persistir. Esto se da en la medida en que solicitantes de refugio con condiciones sexuales y expresiones de género disidentes presentan fragilidades distintas. A pesar de que subsisten avances en las políticas que implementaron el refugio, incluso con la adopción de la Declaración sobre Derechos Humanos, Orientación Sexual e Identidad de Género, la promoción de derechos de igualdad con la población LGBT todavía camina a pasos módicos. Este estudio busca analizar cómo la percepción de vivencias personales de persecución con miras a demostrar pertenecer a un grupo social específico puede reforzar estereotipos de sexualidad y género que acaban por marginar y perjudicar la protección a las personas LGBT, reforzando aspectos de una persecución que puede estar desplazándose del país de origen al país de acogida.

PALABRAS CLAVE: Refugio; Teoría Queer; Derechos humanos; persecución; La migración.

\section{INTRODUÇÃO}

Em um nível global, centenas de milhares de indivíduos são submetidos a violações de direitos humanos em razão de sua condição sexual ou da expressão da identidade de gênero a que pertence. A violência contra estes indivíduos, em especial, mas não apenas, pode ocorrer devido a criação de empecilhos para a segurança, a liberdade, o gozo de direitos políticos, sociais e culturais e, até mesmo, com a negativa do direito à vida e a marginalização destes sujeitos ${ }^{4}$. Na contemporaneidade, ainda constam em setenta e dois o número de Estados

\footnotetext{
${ }^{3}$ United Nations Human Rights - Office Of The High Commissioner. Born free and Equal - Sexual Orientation and Gender Identity in International Human Rights Law. New York and Geneva, 2012. Disponível em: < https://www.ohchr.org/Documents/Publications/BornFreeAndEqualLowRes.pdf>. Acesso em 12 de junho de 2018.

${ }^{4}$ O'FLAHERTY, Michael.; FISCHER, John. Sexual Orientation, Gender Identity and International Human Rights Law: Contextualising the Yogyakarta Principles. Human Rights Law Review, vol. 8, n. 2, p. 222 , 2008.
} 


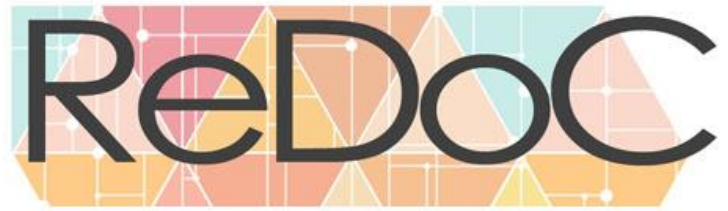

\section{Revista Docência e Cibercultura}

Nacionais que consideram crime o relacionamento entre pessoas do mesmo sexo, sendo que em treze deles se pune com a morte ${ }^{5}$.

Não há pouco o que se dizer sobre a existência de leis, que valem-se de aspectos morais, para restringir a liberdade de expressão em matéria de condição sexual e identidades transgênero, em especial, dezenove países distribuídos entre a África do Norte, Oriente Médio e também a China dedicam-se a editar leis que funcionam de forma a limitar a participação da sociedade civil e a possibilidade de levar assuntos de interesse de indivíduos LGBT para a pauta legislativa que versa sobre políticas públicas e ou processos políticos discutidos nestes locais ${ }^{6}$.

Ainda que, ao longo dos anos, subsistiu crescimento considerável à proteção dos direitos de indivíduos $\mathrm{LGBT}^{7}$, é preciso perceber que apenas a partir de meados dos anos noventa que os direitos sexuais despertaram interesse na pauta dos direitos humanos, em especial após a decisão do Cômite de Direitos Humanos da Organização das Nações Unidas (ONU), acerca do Pacto Internacional Sobre Direitos Civis e Políticos de $1966^{8}$, ao considerar

\footnotetext{
5 “É possível citar que grande parte dos governos do Oriente Médio perseguem homossexuais, ainda que a postura adotada seja, no mínimo, paradoxal. Diz-se isto na medida em que condenam os agentes passivos da relação e aceitam os que são ativos. Perceba que, no início de 2017, um jovem de 15 anos foi lançado de um prédio na cidade de Deir ez-Zor, na Síria. Em outra ótica, no Irã, um homem que tenha sido passivo em um relacionamento homossexual deve ser enforcado, enquanto o ativo receberá chicotadas por 100 vezes. Isto se dá devido aos tribunais de justiça destes países basearem-se na sharia, a lei islâmica, no específico trecho do corão em que os habitantes de Sodoma são mortos por se aproximarem dos homens e não das mulheres. Na Turquia, a homossexualidade pode ser uma das razões para se escapar do alistamento militar, na medida em que os médicos, ao verem fotos e/ou vídeos de um homem mantendo relações com outro homem, na posição de passivo, comprova a homossexualidade e, assim, é dispensado do serviço militar”. Retirado de: TEIXEIRA. DUDA, Porque os terroristas do Estado Islâmico (Isis) executam gays, mas mantêm homossexuais em suas fileiras?. Veja: São Paulo, 9 de fevereiro de 2017. Disponível em: < https://veja.abril.com.br/blog/duvidas-universais/por-que-osterroristas-do-estado-islamico-isis-executam-gays-mas-mantem-homossexuais-em-suas-fileiras/> , Acesso em 12 de junho de 2018. Vide: Association internationale des lesbiennes, gays, bisexuels, trans et intersexes (ILGA): Carroll, A., \& Mendos, L.R., Homophobie d'État 2017 - Une enquête mondiale sur le droit à l'orientation sexuelle : criminalisation, protection et reconnaissance. Genève: ILGA. Mai, 2017, p. 8.

${ }^{6}$ Association internationale des lesbiennes, gays, bisexuels, trans et intersexes (ILGA): Carroll, A., \& Mendos, L.R., Homophobie d'État 2017 - Une enquête mondiale sur le droit à l'orientation sexuelle : criminalisation, protection et reconnaissance. Genève: ILGA. Mai, 2017, p. 9.

${ }^{7}$ É possível afirmar que desde meados dos anos 2000, ainda que com passos tímidos, houve atenção no sentido de criação ou definição de políticas que buscassem definir padrões para lidar com a existência de pessoas nãoheterossexuais e, em ato contínuo, não binárias, pelo mundo. Perceba a criação de organizações e ou políticas internacionais, como a Association internationale des lesbiennes, gays, bisexuels, trans et intersexes (ILGA) e também a Born free and Equal - Sexual Orientation and Gender Identity in International Human Rights Law. ${ }^{8}$ SAIZ, Ignacio. Bracketing Sexuality: Human Rights and Sexual Orientation- A Decade of Development and Denial at the UN. SPW Working Papers, n. 2, nov. 2005.
} 


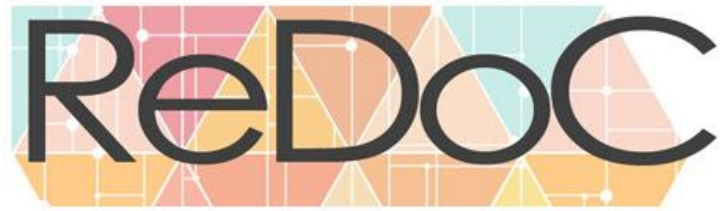

\section{Revista Docência e Cibercultura}

que os direitos de minorias sexuais ${ }^{9}$ também deveriam ser objeto de proteção e, a partir de então, começar a se materializar a existência de um princípio que vedasse a discriminação por condição sexual e/ou a expressão da identidade de gênero $^{10}$.

$\mathrm{O}$ entendimento de que o termo refugiado congrega qualquer pessoa que, temendo ser perseguida por motivos de raça, religião, nacionalidade, grupo social ou opiniões políticas, encontra-se fora do país de sua nacionalidade e que não pode ou, em virtude desse temor, não quer valer-se da proteção desse país ${ }^{11}$, surgiu após o advento da segunda grande guerra e, apesar de não tratar, ao menos de forma específica e explicita, sobre os indivíduos LGBT e a perseguição em virtude de sua condição sexual e a expressão da identidade de gênero, convencionou-se por estabelecer que tais pessoas inserem-se em um grupo social específico ${ }^{12}$, legitimando a concessão de refúgio.

Adentrando as minúcias para a concessão do refúgio ${ }^{13}$, nota-se que existe um viés que interliga a expressão de gênero, a sexualidade e a violência sofrida por um indivíduo, dando origem ao "fundado temor de perseguição" e o pertencimento a determinado grupo social específico - no caso o de pertencer a uma das variáveis de ser $\mathrm{LGBT}^{14}$. A miúda dos fatos, dizse que, a perseguição pode ser considerada como:

\footnotetext{
${ }^{9}$ A adoção do termo "minorias sexuais" se liga a qualquer tipo de grupo estigmatizado ou menosprezado por sua condição sexual, identidade de gênero ou expressão de comportamento. Vide: BAHER, Peter; FLINTERMAN, Cees; SENDERS, Mignon. Innovation and inspiration: Fifty years of the Universal Declaration of Human Rights. Amsterdã: Royal Netherlands Academy of Arts and Sciences, 1999. p. 549.

${ }^{10}$ LEWIS, Rachel. Gay? Prove it: The Politics of Queer anti-deportation activism. Sexualities, vol. 17, n. 8, p. 974-975, 2014.

${ }^{11}$ Conselho de Direitos Humanos das Nações Unidas - Alto Comissariado das Nações Unidas para os Refugiados (ACNUR). Convenção sobre o Estatuto dos Refugiados. Genebra: 1951. Disponível em: < http://www.acnur.org/fileadmin/Documentos/portugues/BDL/Convencao_relativa_ao_Estatuto_dos_Refugiados .pdf>. Acesso em 12 de junho de 2018.

${ }^{12}$ Conselho de Direitos Humanos das Nações Unidas - Alto Comissariado das Nações Unidas para os Refugiados (ACNUR). Convenção sobre o Estatuto dos Refugiados. Genebra: 1951. Disponível em: < http://www.acnur.org/fileadmin/Documentos/portugues/BDL/Convencao_relativa_ao_Estatuto_dos_Refugiados .pdf>. Acesso em 12 de junho de 2018.

${ }^{13}$ Conselho de Direitos Humanos das Nações Unidas - Alto Comissariado das Nações Unidas para os Refugiados (ACNUR). Convenção sobre o Estatuto dos Refugiados. Genebra: 1951. Disponível em: < http://www.acnur.org/fileadmin/Documentos/portugues/BDL/Convencao_relativa_ao_Estatuto_dos_Refugiados .pdf>. Acesso em 12 de junho de 2018.

${ }^{14}$ Opta-se por manter o termo queer devido a impossibilidade de reproduzir fielmente o ônus fortemente pejorativo que o termo incita na cultura norte-americana. Viado, sapatão, bicha, traveco, ou termos assemelhados, se fazem
} 


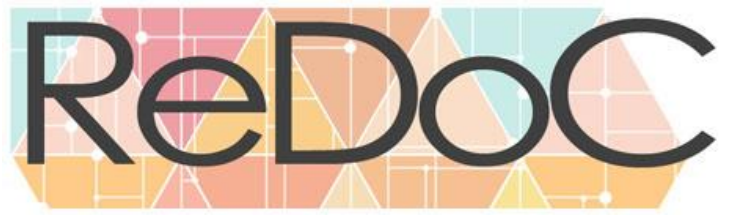

\section{Revista Docência e Cibercultura}

“[...] graves violações de direitos humanos, ameaças à liberdade e outras formas de violência grave. No entanto, formas menos gravosas de violência, se continuadas, também podem constituir uma perseguição. A equiparação de ações a uma perseguição vai depender das circunstâncias do caso, bem como da idade, gênero, opiniões, sentimentos e estado psicológico do solicitante" 15

Por outro lado, quando nos remetemos a comprovação do pertencimento a uma das várias possibilidades de ser LGBT, é que se percebe uma celeuma que pode ser nefasta ao indivíduo solicitante de refúgio. Nota-se que a afirmação de pertencer a este grupo social é diretamente relacionada a perceptiva do indivíduo, em seu discurso sobre si mesmo, de forma claramente subjetiva, consistindo em demonstrar ser passível de violação por ser quem é en $^{16}$ Ou seja, o relevante interesse se concentra em demonstrar a sua própria condição de existência, fazendo com que, até mesmo, tenham surgido situações precárias para avaliar a condição sexual, tal como se percebeu na República Tcheca no ano de $2010^{17}$.

Aufere-se desta constatação que, até certo ponto, é possível que se acolham indivíduos que apresentem diferentes vivências, ocasionando pontos de violência distintos, porém, também se percebe que existe uma lacuna em que se requer um discurso que seja compatível com o conceito de gênero ${ }^{18}$ e de sexualidade. Ocasionando uma possível adequação de

possíveis, apesar de não carregarem a mácula negativa que a terminologia alcançou nos Estados Unidos da América. O termo inglês queer é antigo e possuía, originalmente, uma conotação negative e agressiva contra aqueles que rompiam normas de gênero, em si, homens e mulheres homossexuais. Vide: JAGOSE, Annemarie. Queer Theory - an introduction. New York: New York University Press, 1996.

${ }^{15}$ Conselho de Direitos Humanos das Nações Unidas - Alto Comissariado das Nações Unidas para os Refugiados (ACNUR). Convenção sobre o Estatuto dos Refugiados. Genebra: 1951. Disponível em: < http://www.acnur.org/fileadmin/Documentos/portugues/BDL/Convencao_relativa_ao_Estatuto_dos_Refugiados .pdf $>$. Acesso em 12 de junho de 2018.

${ }^{16}$ LEWIS, Rachel. Gay? Prove it: The Politics of Queer anti-deportation activism. Sexualities, vol. 17, n. 8, p. 958, 2014.

${ }_{17}$ United Nations Human Rights - Office Of The High Commissioner. Comments on the Practice of Phallometry in the Czech Republic to Determine the Credibility of Asylum Claims based on Persecution due to Sexual Orientation. Czech Republic: 2011. Disponível em: <http://www.refworld.org/docid/4daeb07b2.html>, Acesso em 14 junho de 2018.

${ }^{18}$ De forma breve é importante destacar a ideia de distinção entre sexo e gênero surgiu, originalmente, para mitigar a afirmação de que a origem biológica é o destino inenarrável de todo ser humano. Butler preleciona que esta distinção atende à tese de que, por mais que o sexo pareça intratável em termos biológicos, o gênero é culturalmente construído. Logo, não se pode dizer que o gênero se apresenta como um resultado previsível do sexo, quiçá como uma faceta imutável quanto ao sexo. Vide: BUTLER, Judith P. Problemas de gênero: feminismo e subversão da identidade. 10ª ed. - Rio de Janeiro: Civilização Brasileira, p. 25-26, 2016. 


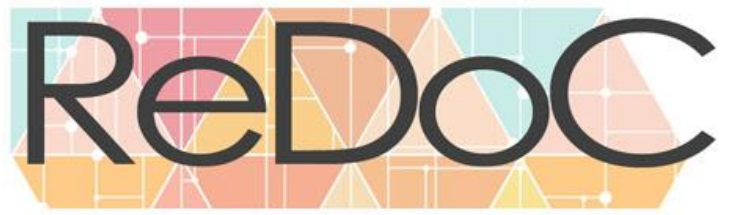

\section{Revista Docência e Cibercultura}

comportamentos, vivências e performances com o objetivo de corresponderem aos anseios dos países nos quais solicitam refúgio.

Portanto, este estudo busca debater a concessão de refúgio com base em sua condição sexual e ou expressão de gênero, sob a ótica da Teoria Queer e na observância de padrões de comportamento para sexualidade e gênero na visão ocidental, e também, em ato contínuo, nas violações perpetradas no próprio processo de obtenção do status de refugiado, em face de outros grupos, como os indivíduos solicitantes em razão de opiniões políticas, nacionalidade, raça ou religião, os quais podem ser verificados de forma objetiva.

\section{A PERSPECTIVA HETERONORMATIVA OCIDENTAL: O SUJEITO, O GENERO E A SEXUALIDADE SOCIALMENTE CONSTRUÍDOS}

Acolhe-se a ideia de que, durante o mundo pós-moderno, as construções sociais e culturais desempenharam um importante papel na vida dos sujeitos da sociedade. Entretanto, não há como se olvidar que nem todas estas construções sociais lograram êxito em se alçarem como bem-sucedidas na caracterização de estruturas tidas como naturais: as distinções entre machos e fêmeas, como preconiza Simone de Beauvoir ${ }^{19}$, o corpo como sujeito passivo das transformações sociais e, até mesmo, o próprio sexo.

Imagina-se que aquilo que o sujeito acredita ser, possui relação direta com a sua identidade, com a substância e os moldes sociais e culturais que foram utilizados com o fim de moldá-lo, enquanto indivíduo pertencente a uma coletividade pré-determinada. O corpo se encontra delimitado desde quando se fala em nascituro. Quando se tem uma ultrassonografia já se inicia um processo de construção que culmina com a prova concreta advinda do nascimento com a designação sexual que se limite em dois sexos constituídos. Perceba que:

A primeira fragmentação do corpo, ou atribuição do sexo, ocorre mediante um processo que chamarei, seguindo Judith Butler, de invocação

${ }^{19}$ BEAUVOIR. Simone de, The Second Sex, trad. E. M. Parshley, Nova York: Vintage, p. 25, 1973. 
performativa. Nenhum de nós escapou dessa interpelação. Antes do nascimento, graças à ecografia - uma tecnologia célere por ser descritiva, mas que não é senão prescritiva - ou no próprio momento do nascimento, nos foi atribuído um sexo feminino ou masculino. ${ }^{20}$

É desta forma precoce que, indivíduos com expressões de gênero e condições sexuais divergentes, necessitam de atenção. É possível aduzir que, além do banimento social e familiar, violências físicas e, até mesmo, sexuais, permanecem na percepção de mundo de indivíduos LGBT solicitantes de refúgio. Data de meados do ano de $2015^{21}$, a percepção pelo Alto Comissariado das Nações Unidas para Refugiados (ACNUR), de que a condição sexual e a expressão de gênero, enquanto conjunturas para a concessão de refúgio restavam inadequadas.

É importante destaca que, para a concessão do refúgio justificado em condição sexual e expressão de gênero, requer-se, contemporaneamente, a transmissão de experiências de perseguição e fuga para adequar-se ao status de refugiado. Perceba que "enquanto solicitações com base em opiniões políticas, nacionalidade, raça ou religião podem ser verificadas concretamente, o pertencimento a um "grupo social” condição sexual ou expressão de gênero depende de uma inteligência subjetiva e interna de identidade pessoal"22.

Isto se dá devido ao fato de que, em se tratando de pessoas LGBT, existe um aspecto que permeia o profano e a vida individual de cada um, internalizadas na memoria pessoal do indivíduo, que acarretam a exposição de características que impactam diretamente no modo de vida do indivíduo, tal como assédio sexual, tortura, auto repressão, vergonha ${ }^{23}$, sendo evidente

\footnotetext{
${ }^{20}$ PRECIADO. Beatriz, Manifesto Contrassexual, trad. Maria Paula Gurgel Ribeiro, São Paulo: n-1 edições, p. 130,2014

${ }^{21}$ UN High Commissioner for Refugees (UNHCR), Protecting Persons with Diverse Sexual Orientations and Gender Identities: A Global Report on UNHCR's Efforts to Protect Lesbian, Gay, Bisexual, Transgender, and Intersex Asylum-Seekers and Refugees, December 2015, Disponível em: <http://www.refworld.org/docid/566140454.html> Acesso em 16 de Junho de 2018.

${ }^{22}$ BERG, Laurie; MILLBANK, Jenni, Constructing the Personal Narratives of Lesbian, Gay and Bisexual Asylum Claimants. Journal of Refugee Studies, vol. 22, n. 2, p. 203, 2009.

${ }^{23}$ BERG, Laurie; MILLBANK, Jenni. Constructing the Personal Narratives of Lesbian, Gay and Bisexual Asylum Claimants. Journal of Refugee Studies, vol. 22, n. 2, p. 209, 2009.
} 


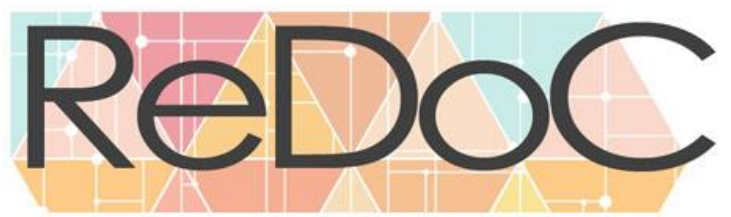

\section{Revista Docência e Cibercultura}

que a exposição destas ocorrências não são obtidas de forma fácil e agradável, e sim através de um processo sofrível e extremamente desagradável aos indivíduos interessados no refúgio ${ }^{24}$.

A compreensão ocidental destas revelações tem permitido que aberrações jurídicas venham sendo propostas. Neste sentido ${ }^{25}$, no ano de 2010, a Suprema Corte do Reino Unido, proveu decisão no sentido de que tão somente indivíduos "notadamente homossexuais" ou ainda "homossexuais com vida sexual ativa" seriam os que se enquadravam como grupo social específico e que, em ato continuo, necessitavam de proteção. Por outro lado, os que "optavam por viver discretamente em sociedade", não estariam contidos neste grupo. Relaciona-se também a ideia de que indivíduos bissexuais, poderiam envolver-se sexualmente com uma pessoa do sexo oposto para evitar a perseguição, e desta forma não ser abarcada pelo instituto do refúgio ${ }^{26}$.

Em outros relatos, noticia-se que Estados também vem recusando a concessão de refúgio ao levar em conta que, caso os indivíduos solicitantes se importassem com a própria segurança, estes não necessitariam do refúgio. Considerando que, ao evitar possíveis comportamentos que os caracterizassem como LGBT, principalmente em sociedade, abrindo mão de um relacionamento público ou até extirpando-os de sua vida, nada teriam a temer ${ }^{27}$. Este raciocínio pode levar a crer que o próprio indivíduo que busca o status de refugiado é vítima de sua própria torpeza, já que não pode ter sua vivência plena em seu país de origem devido ao seu próprio comportamento e performance de gênero.

É neste sentido que, na contemporaneidade, se faz sugerido que a alusão de que pessoas LGBT pertencem a um grupo social específico, não se mostra capaz de garantir que tais

\footnotetext{
${ }^{24}$ GRUNGRAS, Neil. Support, Not Stereotypes, When Interviewing LGBTI Refugees. The Huffington Post, ago. 2012. Disponível em: <http://www.huffingtonpost.com/neil-grungras/lgbti-refugees_b_1766387.html>. Acesso em 19 de junho de 2018.

${ }^{25}$ LEWIS, Rachel. Gay? Prove it: The Politics of Queer anti-deportation activism. Sexualities, vol. 17, n. 8, p. 971, 2014.

${ }^{26}$ JANSEN, Sabine; SPIJKERBOER, Thomas, Fleeing Homophobia: Asylum Claims Related to Sexual Orientation and Gender Identity in Europe. Amsterdã: COC Nederland, p. 85, 2011.

${ }^{27}$ MILLBANK, Jenni. From Discretion to Disbelief: Recent Trends in Refugee Determinations on the Basis of Sexual Orientation in Australia and the United Kingdom. International Journal of Human Rights, vol. 13, n. 2/3, p. 397, 2009.
} 


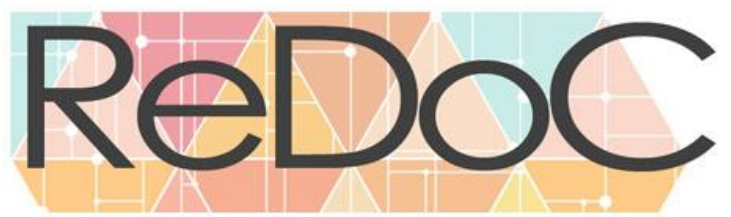

\section{Revista Docência e Cibercultura}

indivíduos possam gozar verdadeiramente do instituto do refúgio. Isto ocorre devido a influência que padrões performáticos de gêneros são vivenciados pelos países ocidentais e em como estes são reproduzidos na administração de cada país ${ }^{28}$. Perceba que, até mesmo, questiona-se a participação do solicitante de refúgio, especificamente em ambientes LGBT $^{29}$, para que assim se possa, ao menos neste raciocínio, fazer prova da condição sexual ou da expressão de gênero destes indivíduos.

Não que, estes atos, realmente assegurem o pertencimento a um grupo de identidade em seu país, porém, são estas as noções de adequação sexual, a que cotidianamente tem-se $\operatorname{adotado}^{30}$ para a concessão do refúgio. Ou seja, são verdadeiros estereótipos de análise corporal, que podem acabar por desprezar pessoas que não se enquadrem nos padrões de contraheteronorma esperados por cidadãos LGBT do ocidente ${ }^{31}$, em especial de mulheres lésbicas que não possuam trejeitos masculinos, gays que se comportem de forma não afeminada e pessoas que casaram-se ou tenham tido filhos ${ }^{32}$.

Também existem outros posicionamentos que alegam que as minorias sexuais solicitantes de refúgio seriam "depravados, de que não possuem relacionamentos estáveis e são promíscuos ou de que solicitantes bissexuais estariam em dúvida sobre sua sexualidade" 33 , comungando com o entendimento de que estas pessoas são objetos de ataque em seus países

\footnotetext{
${ }^{28}$ MILLBANK, Jenni. Gender, Visibility and Public Space in Refugee Claims on the Basis of Sexual Orientation. Seattle Journal for Social Justice, vol. 1, n. 3, p. 726-729, dec. 2002.

${ }^{29}$ MILLBANK, Jenni. From Discretion to Disbelief: Recent Trends in Refugee Determinations on the Basis of Sexual Orientation in Australia and the United Kingdom. International Journal of Human Rights, vol. 13, n. 2/3, p. 394, 2009.

${ }^{30}$ MILLBANK, Jenni. From Discretion to Disbelief: Recent Trends in Refugee Determinations on the Basis of Sexual Orientation in Australia and the United Kingdom. International Journal of Human Rights, vol. 13, n. 2/3, p. 396, 2009.

${ }^{31}$ BERG, Laurie; MILLBANK, Jenni. Constructing the Personal Narratives of Lesbian, Gay and Bisexual Asylum Claimants. Journal of Refugee Studies, vol. 22, n. 2, p. 204, 2009.

32 JANSEN, Sabine; SPIJKERBOER, Thomas. Fleeing Homophobia: Asylum Claims Related to Sexual Orientation and Gender Identity in Europe. Amsterdã: COC Nederland, p. 42, 2011.

${ }^{33}$ BERNARDES, Pedro Henrique Dias Alves. Esconder para sobreviver: uma perspectiva queer sobre refugiados LGBTI+. <http://www.enadir2017.sinteseeventos.com.br/arquivo/downloadpublic2?q=YToyOntzOjY6InBhcmFtcyI7czoz NDoiYToxOntzOjEwOiJJRF9BUIFVSVZPIjtzOjM6IjIxOCI7fSI7czoxOiJoIjtzOjMyOiJ1MWNkYTUxOTBIZ mZmZmE3ZjdmNTY3Zjk5YTY5YzdkOSI7fQ\%3D\%3D>, p. 5, Acesso em 19 de junho de 2018.
} 


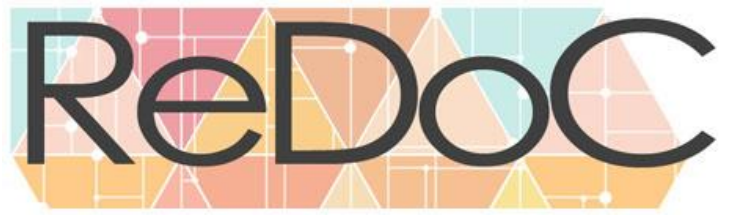

\section{Revista Docência e Cibercultura}

nativos por serem tidos como libidionosos e que, em outro sentido, são corpos "normais" e “socialmente aceitáveis" com vistas a conseguir proteção em outros países ${ }^{34}$.

Portanto, nota-se que há verdadeiros contrapesos estatais para filtrar experiências sexuais que coadunem com as perspectivas ocidentais, levando a ideias pré-estabelecidas da sexualidade entre cidadãos LGBT. Quer dizer que o solicitante deve ter transpassado e vislumbrado, a si mesmo, dentre uma relação interpessoal plausível, para assim realizar o convencimento de que realmente enquadra-se na restrita categoria de cidadão abjeto ${ }^{35}$. Conduzindo a própria ideia da heterossexualidade como norma, em que, um cidadão LGBT que não demonstre, ou tenha uma performance de forma a ocultar ou não transparecer sua condição sexual, este mesmo indivíduo poderá ser regularmente aceito na sociedade e transitar livremente pelos espaços.

Curioso é que, em maior ou menor grau, espera-se que os indivíduos, ao adentrarem em um novo território, teoricamente seguro, demonstrem padrões de comportamento ocidentais nos quais se perceba atos, gestos, falas, consumos e hábitos comuns a pessoas LGBT. Ignorando-se toda a percepção de que o gênero é fluído, é performático e que, poucos dias atrás, estas pessoas ainda subsistiam por esconder suas sexualidades e identidades de gênero, para assegurar sua sobrevivência e ou integridade em seus países de origem.

Dizer que o gênero é performativo, traduz o sentido de que este produz uma série de efeitos. Nós agimos e andamos e falamos de forma que consolidam uma impressão de ser um

\footnotetext{
${ }^{34}$ NAYAK, Meghana. Who Is Worthy of Protection?: Gender-Based Asylum and U.S. Immigration Politics . EUA: Oxford University Press, 2015. 272 p. conforme citado por BERNARDES, Pedro Henrique Dias Alves. Esconder para sobreviver: uma perspectiva queer sobre refugiados LGBTI+. <http://www.enadir2017.sinteseeventos.com.br/arquivo/downloadpublic2?q=YToyOntzOjY6InBhcmFtcyI7czoz NDoiYToxOntzOjEwOiJJRF9BUlFVSVZPIjtzOjM6IjIxOCI7fSI7czoxOiJoIjtzOjMyOiJlMWNkYTUxOTB1Z mZmZmE3ZjdmNTY3Zjk5YTY5YzdkOSI7fQ\%3D\%3D>, p. 5, Acesso em 19 de junho de 2018.

${ }^{35}$ Butler enuncia que, o gênero "é a estilização repetida do corpo, um conjunto de atos repetidos no interior de uma estrutura reguladora altamente rígida, a qual se cristaliza no tempo para produzir a aparência de uma substância, de uma classe natural de ser". Deste modo, ao acompanhar o pensamento de Judith Butler, o gênero se constitui não de um conjunto de valores culturais submetidos ao corpo, tampouco com a interpretação que este corpo conceda, quiçá ao ser homem ou ser mulher. Ele significa um conjunto de regras impostas, perpetuadas e realocadas sobre o corpo de forma a consubstanciarem na aparência desejada de forma a conceder um status válido aos indivíduos. Vide: BUTLER, Judith P. Problemas de gênero: feminismo e subversão da identidade. $10^{\mathrm{a}}$ ed. - Rio de Janeiro: Civilização Brasileira, p. 59, 2016.
} 


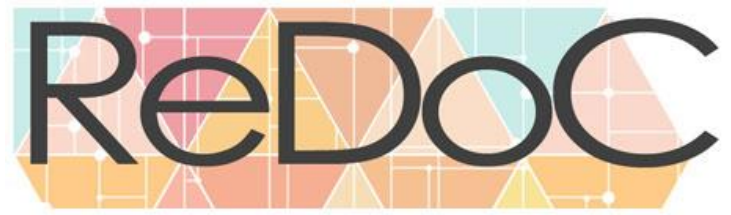

\section{Revista Docência e Cibercultura}

homem ou de ser uma mulher. Nós tomamos partido como se este ser um homem ou este ser uma mulher fosse na verdade algo que simplesmente é uma verdade sobre nós, é um fato sobre nós. Na verdade, é um fenômeno que tem sido produzido todo o tempo, e reproduzido todo o tempo. Então, dizer que o gênero é performativo é dizer que ninguém pertence a um gênero desde sempre. Daí se poder defender a existência de todo um conjunto de posturas e de artefatos que se consubstanciam num reconhecimento dos sujeitos sociais.

Contudo, isto é um relato, um fenômeno, uma circunstância que não deveria, ao menos em tese, ser imposta por padrões estereotipados e ocidentais, ainda mais como requisito para a concessão de refúgio. Perceba que estes indivíduos devem mascarar suas sexualidades por anos a fio, assegurando, por muitas vezes, sua sobrevivência em seus países de origem, para que, então, necessitem revelar de forma explicita, com o objetivo de receberem proteção em novos países e, ainda assim, serem forçados a adotar novamente um véu de encobrimento caso haja negativa de concessão do refúgio, o que corrobora para uma profunda opressão contra grupos historicamente marginalizados ${ }^{36}$.

\section{REFÚGIO: UM VISLUMBRE SOBRE A ÓTICA DA PERFORMANCE DE GÊNERO}

Há de se falar que, ao decorrer dos anos, tornou-se imperativa a busca por mecanismos e justificativas para as abjeções existentes. Se diz isto, pois, no momento em que se busca uma explicação e uma adequação para a homossexualidade, ainda que não mais a tenhamos como uma patologia ${ }^{37}$, em sentido contrário se manifesta a cultura heteronormativa como uma

\footnotetext{
${ }^{36}$ HELLER, Pamela. Challenges Facing LGBT Asylum-Seekers: The Role of Social Work in Correcting Oppressive Immigration Processes. Journal of Gay \& Lesbian Social Services, vol. 21, p. 304-308, 2009.

${ }^{37}$ O homossexualismo passou a existir na CID a partir da 6a Revisão (1948), na Categoria 320 Personalidade Patológica, como um dos termos de inclusão da subcategoria 320.6 Desvio Sexual. Manteve-se assim a 7a Revisão (1955), e na 8a Revisão (1965) o homossexualismo saiu da categoria "Personalidade Patológica" ficou na categoria "Desvio e Transtornos Sexuais" (código 302), sendo que a subcategoria específica passou a 302.0 Homossexualismo. A 9a. Revisão (1975), atualmente em vigor, manteve o homossexualismo na mesma categoria e subcategoria, porém, já levando em conta opiniões divergentes de escolas psiquiátricas, colocou sob o código a seguinte orientação "Codifique a homossexualidade aqui seja ou não a mesma considerada transtorno mental". Vide: LAURENTI. Ruy, Homossexualismo e a Classificação Internacional de Doenças. Rev. Saúde Pública [online]. 1984, vol.18, n.5, pp.344-347. ISSN 0034 8910. http://dx.doi.org/10.1590/S0034-89101984000500002.
} 


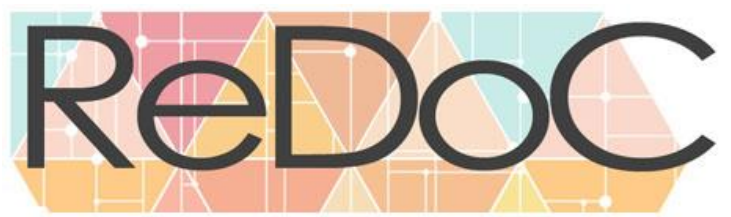

\section{Revista Docência e Cibercultura}

variável possível, naturaliza-se a heterossexualidade enquanto encobre-se um mecanismo que reverbera o caráter anormal das sexualidades dela discordantes.

Por vezes adota-se um parâmetro que promove uma maior segregação e desassossego a parcelas da sociedade, ao revés de inquietar-se para descobrir as raízes que consideram que algumas pessoas são anormais, inaceitáveis, inválidas ao passo de que outras são habitualmente aceitas no seio social. Na medida em que, até os dias atuais, ainda subsiste uma necessidade de adequação entre o sexo biológico, o gênero e a expressão do desejo humano, mantendo um dualismo entre a heterossexualidade e todas as expressões de gênero que dela discordem.

É a partir destes desafios que a perspectiva da teoria queer denota os desafios que se apresentam na seara dos direitos humanos das pessoas em situação de refúgio. É precioso destacar que esta teoria surgiu em clara contraposição as estruturas rígidas e justapostas que restringiam a vivência humana, ao considera-la como "um impulso crítico em relação à ordem sexual contemporânea" 38 , onde houve uma resiginificação de um termo que denotava perversão, um verdadeiro xingamento para todos aqueles que desenvolviam-se de forma a romper com padrões de sexualidade e gênero como unidades restritas e inelásticas.

O queer surgiu a partir da concepção de que a sexualidade humana é um dispositivo histórico de poder, em que se busca a regulação nas sociedades ocidentais pela inserção do sexo em sistemas que se dedicam a prática e a discursos sociais, como a cultura, as prospecções morais, e as noções da natureza do ser humano, a qual refletia a sexualidade como um regime que se dedica a regulação das relações sociais, através de instituições e práticas que propõem o reforço de noções estáticas e firmas sobre o gênero e a sexualidade ${ }^{39}$.

Neste viés, a teoria queer elenca o sujeito sempre submetido a um devir, em um caráter permanentemente transitório, de fronteiras sexuais móveis, onde as circunstâncias que versam

\footnotetext{
${ }^{38}$ MISKOLCI, Richard. Teoria Queer: um aprendizado pelas diferenças / Richard Miskolci. - 2. Ed. Rev. E Ampl., 2. Reimp. - Belo Horizonte: Autêntica Editora: UFOP - Universidade Federal de Ouro Preto, 2015. Série Cadernos da Diversidade; 6. P. 21.

${ }^{39}$ MISKOLCI, Richard. Teoria Queer: um aprendizado pelas diferenças / Richard Miskolci. - 2. Ed. Rev. E Ampl., 2. Reimp. - Belo Horizonte: Autêntica Editora: UFOP - Universidade Federal de Ouro Preto, 2015. Série Cadernos da Diversidade; 6. P. 25.
} 


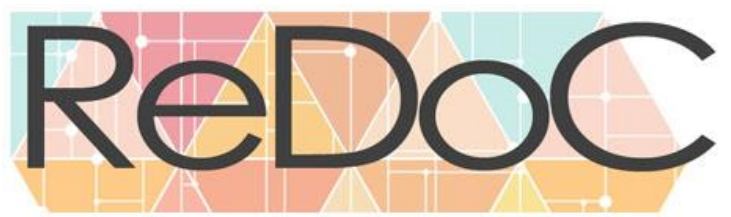

\section{Revista Docência e Cibercultura}

sobre identidades "naturais" de sexo e gênero, não são aceitas, permitindo uma nova compreensão sobre categorias anteriormente fixas e restritivas, suscitando uma compreensão elástica e atenta a necessidade de que grupos historicamente marginalizados possam exercitar a sua sexualidade, o gênero e o desejo sexual ${ }^{40}$. Este caráter flutuante que a teoria queer apregoa a sexualidade humana, pode ser percebido também no âmbito das discussões entre o direito internacional dos refugiados e os direitos humanos ${ }^{41}$.

Estas noções derivam da compreensão de que, a sexualidade humana, não pode ser percebida dentro de uma ótica binária e restrita. E sim, por outro lado, deve ser observada em uma ótica que estabeleça uma compreensão universal acerca das performances de gênero e desejo sexual, os quais podem ser percebidos e exercidos de numerosas formas, em diversas sociedades e em concepções que não se amoldam as proposituras experimentadas nos países ocidentais, nos quais ainda se vigora a tensão que elenca a cisheteronorma, a qual apresenta a construção social, em categorias rígidas e excludentes, que restringem a identidade individual e social.

É precioso perceber que, a própria seara dos direitos humanos atua de forma a trazer a discussão sobre a necessidade de novas concepções acerca das noções de gênero e sexualidade. A concepção ocidental acerca das performances de gênero e sobre a sexualidade dos indivíduos não estão contidas, tão somente, nos contextos vivenciados nestas culturas. Não é difícil perceber que as construções sociais criadas no ocidente, não são representativas das expressões do oriente, e o próprio discurso que tece a universalidade dos direitos humanos, por sua vez, deve se ater a estas variáveis.

Noções culturais, sociais e políticas são próprias de cada sociedade que as vivenciam ${ }^{42}$. Estas vivencias e características acabam sendo internalizadas pelos indivíduos e passam por

\footnotetext{
${ }^{40}$ ROCHA, Cássio Bruno Araújo. Um pequeno guia ao pensamento, aos conceitos e à obra de Judith Butler. Cadernos Pagu, n. 43, p. 507-516, jul./dez. 2014

${ }^{41}$ GROSS, Aeyal. Queer Theory and International Human Rights Law: Does Each Person Have a Sexual Orientation?. Proceedings of the Annual Meeting (American Society of International Law), vol.101, p. 129-132. 2007. Disponível em: <http://www.jstor.org/stable/25660175>. Acesso em 3 ago. 2018.

${ }^{42}$ BUTLER, Judith P. Problemas de gênero: feminismo e subversão da identidade. $10^{\mathrm{a}}$ ed. - Rio de Janeiro: Civilização Brasileira, p. 122, 2016.
} 


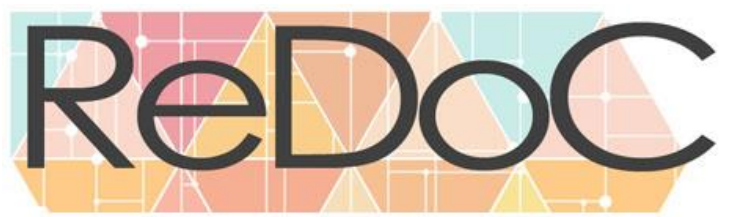

\section{Revista Docência e Cibercultura}

uma averiguação e compatibilidade quando da análise das solicitações de refúgio para as minorias sexuais. Isto pois, é adotado nas solicitação de refúgio, em especial quando de minorias sexuais, que se busque vislumbrar condutas que se encontravam reprimidas e ocultas em seus países de origem, com vistas a adequação de prospecções pré-constituídas sobre gênero e sexualidade, influenciando o deferimento do pedido de refúgio ${ }^{43}$.

Note que, para que a concessão do refúgio ocorra, é preciso que haja a confissão de aspectos personalíssimos da vida de pessoas LGBT, as quais podem não se expressar com o vigor necessário em virtude de o ambiente e circunstância em que se encontram não serem favoráveis ${ }^{44}$, favorecendo a preponderância de vergonha e humilhação. Subsiste também um paradigma de que, numerosas condutas praticadas por estas pessoas também podem constituirse de atos que remetam a crimes e ou a violação de regras impostas durante a vida destes indivíduos, prejudicando a forma como se confessam perante outras sociedades em face da percepção que eles detêm sobre suas próprias vivências ${ }^{45}$.

Além disto, também é preciso destacar, a necessidade imperativa de que os agentes concedentes de refúgio, consigam adequar as realidades experimentadas pelos requerentes, em comportamentos padronizados e normativos vistos sob uma ótica própria em cada Estado. Portanto, para que solicitações de refúgio sejam aceitas, devem coincidir com às prospecções dos agentes do país concedente em face das narrativas dos solicitantes ${ }^{46}$. Logo, a questão paradigmática que versa sobre a concessão do refúgio de pessoas queer, encontra-se justificada na medida em que devem ter sido experimentadas situações e acontecimentos que sejam plausíveis sob a ótica dos agentes, como ocorrências que ensejem a concessão do refúgio.

\footnotetext{
${ }^{43}$ LEWIS, Rachel. Gay? Prove it: The Politics of Queer anti-deportation activism. Sexualities, vol. 17, n. 8, p. 974, 2014.

${ }^{44}$ SHUMAN, Amy; BOHMER, Carol. Gender and Cultural Silences in the Political Asylum Process. Sexualities, vol. 17, n. 8, p. 942, 2014.

${ }^{45}$ SHUMAN, Amy.; BOHMER, Carol. Gender and Cultural Silences in the Political Asylum Process. Sexualities, vol. 17, n. 8, p. 943, 2014.

${ }^{46}$ SHUMAN, Amy.; BOHMER, Carol. Gender and Cultural Silences in the Political Asylum Process. Sexualities, vol. 17, n. 8, p. 947, 2014.
} 


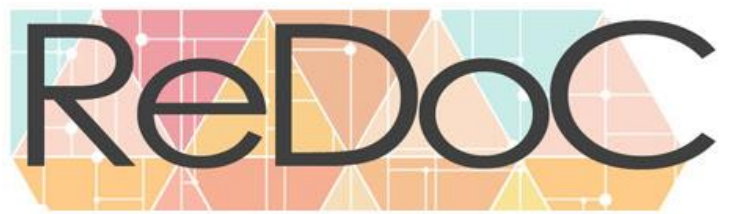

\section{Revista Docência e Cibercultura}

Isto acarreta, em ato contínuo, a necessidade que se reproduzam performances de gênero e expressão de desejos sexuais, compatíveis com a percepção dos países concedentes de refúgio, como sendo atos que tendam a causar uma perseguição e ou ameaça. Quando o viés de conduta esperado para um homem homossexual, na concepção ocidental, não seja facilmente percebida, distanciando-se das normas de comportamento ideais para a concessão, a solicitação de refúgio poderá ser negada, de sobremaneira quando a perseguição não se dê em espaços públicos ${ }^{47}$.

Neste viés, é possível sugerir que a concessão de refúgio para um homem homossexual, necessite implicar, em maior ou menor grau, que em seu país de origem a sua conduta pública seja impregnada por pechas que favoreçam a perseguição, como as vivenciadas por indivíduos que atuem na defesa e promoção de causas de igualdade entre as pessoas LGBT. De forma diversa, não se considera as vivências e perseguições que podem ser experimentadas dentro do ambiente privado e, em especial, no âmbito familiar. É possível suscitar que, tal como em outras formas de violência de gênero contra a mulher, as agressões se deem, de forma proeminente, dentro dos ambientes privados, sejam eles dentro de suas relações de emprego ou nas relações de cunho familiar.

Está deficiência é demonstrada quando da equiparação entre as solicitações de refúgio por homens homossexuais e mulheres lésbicas. Apesar de participarem de relações que demonstram as mesmas ofensas, em tese, a heteronormatividade, países como os Estados Unidos da América e a Inglaterra ${ }^{48}$, identificam um índice de ocorrências menores envolvendo refúgios em que a protagonista seja uma mulher homossexual. Envolve-se, neste sentido, a pragmática que ataca e vilipendia o direito ao refúgio, em virtude de uma tendência a desconsiderar as relações privadas, por não demonstrem claramente as máculas a que um indivíduo LGBT é submetido, reforçando a imprecisão com a qual as relações de gênero e poder são tratadas pelos Estados.

\footnotetext{
${ }^{47}$ SHUMAN, Amy; BOHMER, Carol. Gender and Cultural Silences in the Political Asylum Process. Sexualities, vol. 17, n. 8, p. 947, 2014.

48 SHUMAN, Amy.; BOHMER, Carol. Gender and Cultural Silences in the Political Asylum Process. Sexualities, vol. 17, n. 8, p. 947, 2014.
} 


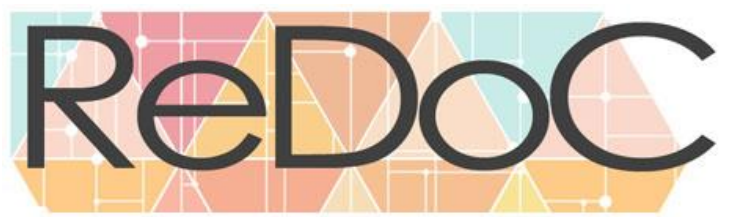

\section{Revista Docência e Cibercultura}

Ao mesmo tempo em que o refúgio deveria ser visto como uma política de abrigo e acolhimento, ela também pode ser percebida e vivenciada como um reforço a condutas que segregam e reprimem seres abjetos e com performances de gênero divergentes, em especial por deturparem a ideia de gênero e sexo como categorias binárias e excludentes. Neste sentido, pessoas que divergem destas categorias restritivas, precisam apresentar-se em consonância com ideais ocidentais e heteronormativos que atentem contra o sistema cisgênero, necessitando que as suas homossexualidades, lesbiandades, bissexualidades, transsexualidades e demais formas de expressões de desejo sexual e gênero se adequem as concepções que possuem um caráter excludente as minorias sexuais ${ }^{49}$.

É abismático que, pessoas LGBT necessitem moldar seus corpos, atitudes e expressões para adequar-se a perspectivas da hetero-norma, ainda que suas identidades não se configurem como normativas, se mostra imperativo a adequação às expectativas de gênero construídas em outras realidades e com aspectos culturais distintos para que se obtenha o refúgio. Ocasionando um processo de elaboração de identidades que, através de uma fala oriunda de perspectivas dominantes, são reformuladas e aparentemente reconhecem direitos de grupos marginalizados. Contudo, não se atrevem a perceber que as mesmas falas que construíram identidades e balizamentos sobre os corpos, transcrevem, na verdade, práticas que são vistas como avessas a pessoas queer e reforçam condutas que levam a abjeção destes corpos na sociedade ${ }^{50}$.

\section{CONCLUSÕES}

O cotejo aqui avençado, permite perceber que, as atuais formas de controle das solicitações de refúgio, em virtude da condição sexual e identidade de gênero dos solicitantes, tendem a reverberar e concretizar formas de violência contra pessoas queer, seja elas de forma simbólica ou estrutural, na medida em que podem acarretar a devolução dos indivíduos aos países de origem e ocasionar condições drásticas a estas pessoas ${ }^{51}$. Visto que, subsiste a

\footnotetext{
${ }^{49}$ NAYAK, Meghana. Who Is Worthy of Protection?: Gender-Based Asylum and U.S. Immigration Politics . EUA: Oxford University Press, 2015. 272 p.

${ }^{50}$ LEWIS, Rachel. Gay? Prove it: The Politics of Queer anti-deportation activism. Sexualities, vol. 17, n. 8, p. 974, 2014.

${ }^{51}$ NAYAK, Meghana. Who Is Worthy of Protection?: Gender-Based Asylum and U.S. Immigration Politics . EUA: Oxford University Press, 2015. 272 p
} 


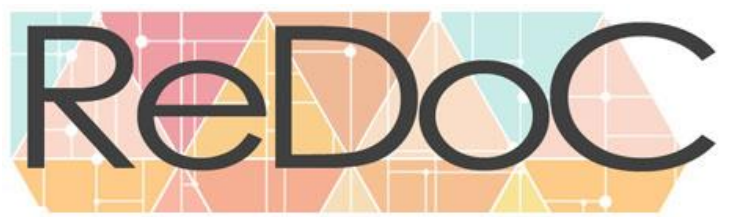

\section{Revista Docência e Cibercultura}

necessidade de que o solicitante de refúgio demonstre de forma criteriosa as situações que o acometiam em seus países, na medida em que os Estados buscam a revelação de vivências que se compatibilizem com as perspectivas ocidentais.

Além de se mostrar como uma aberração, visto que a experimentação de situações de perseguição de gênero e condição sexual, são distintas em razão das culturas e das sociedades, e também dependem de esferas públicas e privadas. Neste sentido, seria relevante a indicação de que as experiências de uma pessoa em determinada sociedade, não necessariamente se adequam as expectativas de outros indivíduos em uma realidade distinta, sendo que a conduta dos Estados concedentes de refúgio deveriam pautar-se na perspectiva de que outras formas de vida são possíveis em cada país ${ }^{52}$.

Tendo em vista que os mecanismos de controle ainda esbarram em concepções normativas, seja na adequação entre sexo e gênero ou ainda na expressão de desejo sexual, demonstrando assim uma prática que exclui e marginaliza as pessoas, trazendo a ideia de que as identidades são fixas e os comportamentos dela derivados são todos categorizados e esperados. Acarretando uma adequação racional dos indivíduos, anulando suas variáveis pessoais e buscando restringir-se em definições fixas, aceitáveis e esperadas, as quais encontram-se reguladas e dispostas como normas imperativas aos indivíduos ${ }^{53}$.

E isto, neste sentido normativo e restritivo indicado e moldado aos indivíduos queer, é justamente o contrário do que apregoa uma categoria marcada por imprecisões e aspectos de fluidez que esta terminologia veste, ao abandonar fáceis definições restritas e recusando-se a fixar parâmetros de identidades sexuais e de gênero, subvertendo a própria concepção da universalidade de direitos, tão cara e apregoada ao universo dos direitos humanos. Ao se falar em condições humanas, não deveria pautar-se de forma a tratar os indivíduos como objetos de

\footnotetext{
${ }^{52}$ SHAKHSARI, Sima. The queer time of death: Temporality, geopolitics, and refugee rights. Sexualities, vol. 17, n. 8, p. 998-1015, 2014.

${ }^{53}$ SHAKHSARI, Sima. The queer time of death: Temporality, geopolitics, and refugee rights. Sexualities, vol. 17, n. 8, p. 998-1015, 2014.
} 


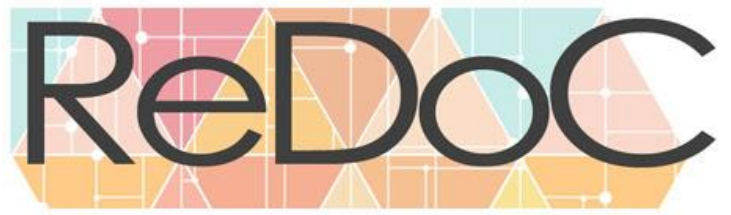

\section{Revista Docência e Cibercultura}

existir que se produza um lastro probatório sobre a expressão de gênero e ou condição sexual de pessoas queer.

Diante de tantas imprecisões, indicar-se-ia de forma lógica que a vivência de um indivíduo possa ser abstraída em observância as narrativas de vida e perseguição que carregam consigo $^{54}$, sem que isto tenha a necessidade de adequar-se as expectativas do ouvinte, e sim questionando a si mesmos sobre se eventuais inconsistências seriam determinantes para a negativa do refúgio ${ }^{55}$. Assim, questiona-se se as relações de poder e sujeição seriam determinantes e excludentes, dada a complexidade que permeia as relações de gênero e sexualidade no espectro humano.

\section{Referências}

Association internationale des lesbiennes, gays, bisexuels, trans et intersexes (ILGA): Carroll, A., \& Mendos, L.R., Homophobie d'État 2017 - Une enquête mondiale sur le droit à l'orientation sexuelle : criminalisation, protection et reconnaissance. Genève: ILGA. Mai, 2017, p. 8.

BEAUVOIR. Simone de, The Second Sex, trad. E. M. Parshley, Nova York: Vintage, p. 25, 1973.

BERNARDES, Pedro Henrique Dias Alves. Esconder para sobreviver: uma perspectiva $\begin{array}{llll}\text { queer } & \text { sobre } & \text { refugiados }\end{array}$ <http://www.enadir2017.sinteseeventos.com.br/arquivo/downloadpublic2?q=YToyOntzOjY6 InBhcmFtcyI7czozNDoiYToxOntzOjEwOiJJRF9BUlFVSVZPIjtzOjM6IjIxOCI7fSI7czoxOi JoIjtzOjMyOiJlMWNkYTUxOTBlZmZmZmE3ZjdmNTY3Zjk5YTY5YzdkOSI7fQ\%3D\%3 D>, p. 5, Acesso em 19 de junho de 2018.

\footnotetext{
${ }^{54}$ SHUMAN, Amy.; BOHMER, Carol. Gender and Cultural Silences in the Political Asylum Process. Sexualities, vol. 17, n. 8, p. 947, 2014.

55 SHUMAN, Amy.; BOHMER, Carol. Gender and Cultural Silences in the Political Asylum Process. Sexualities, vol. 17, n. 8, p. 947, 2014.
} 


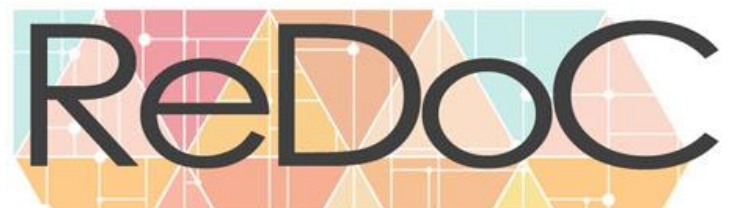

\section{Revista Docência e Cibercultura}

BERG, Laurie; MILLBANK, Jenni. Constructing the Personal Narratives of Lesbian, Gay and Bisexual Asylum Claimants. Journal of Refugee Studies, vol. 22, n. 2, p. 204, 2009.

BUTLER, Judith P. Problemas de gênero: feminismo e subversão da identidade. $10^{\mathrm{a}}$ ed. Rio de Janeiro: Civilização Brasileira, p. 122, 2016.

Conselho de Direitos Humanos das Nações Unidas - Alto Comissariado das Nações Unidas para os Refugiados (ACNUR). Convenção sobre o Estatuto dos Refugiados. Genebra: 1951. Disponível em:

http://www.acnur.org/fileadmin/Documentos/portugues/BDL/Convencao_relativa_ao_Estatut o_dos_Refugiados.pdf $>$. Acesso em 12 de junho de 2018.

GROSS, Aeyal. Queer Theory and International Human Rights Law: Does Each Person Have a Sexual Orientation?. Proceedings of the Annual Meeting (American Society of International Law), vol.101, p. 129-132. 2007. Disponível em: <http://www.jstor.org/stable/25660175>. Acesso em 3 ago. 2018.

GRUNGRAS, Neil. Support, Not Stereotypes, When Interviewing LGBTI Refugees. The Huffington Post, ago. 2012. Disponível em: <http://www.huffingtonpost.com/neilgrungras/lgbti-refugees_b_1766387.html>. Acesso em 19 de junho de 2018.

HELLER, Pamela. Challenges Facing LGBT Asylum-Seekers: The Role of Social Work in Correcting Oppressive Immigration Processes. Journal of Gay \& Lesbian Social Services, vol. 21, p. 304-308, 2009

JANSEN, Sabine; SPIJKERBOER, Thomas. Fleeing Homophobia: Asylum Claims Related to Sexual Orientation and Gender Identity in Europe. Amsterdã: COC Nederland, p. 42, 2011.

LEWIS, Rachel. Gay? Prove it: The Politics of Queer anti-deportation activism. Sexualities , vol. 17, n. 8, p. 974, 2014. 


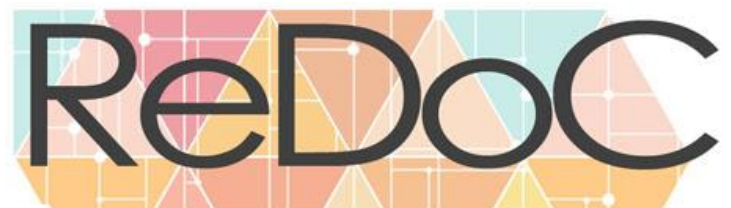

Revista Docência e Cibercultura

MILLBANK, Jenni. Gender, Visibility and Public Space in Refugee Claims on the Basis of Sexual Orientation. Seattle Journal for Social Justice, vol. 1, n. 3, p. 726-729, dec. 2002.

From Discretion to Disbelief: Recent Trends in Refugee Determinations on the Basis of Sexual Orientation in Australia and the United Kingdom. International Journal of Human Rights, vol. 13, n. 2/3, p. 394, 2009.

MISKOLCI, Richard. Teoria Queer: um aprendizado pelas diferenças / Richard Miskolci. - 2. Ed. Rev. E Ampl., 2. Reimp. - Belo Horizonte: Autêntica Editora: UFOP - Universidade Federal de Ouro Preto, 2015. - Série Cadernos da Diversidade; 6. P. 25.

NAYAK, Meghana. Who Is Worthy of Protection?: Gender-Based Asylum and U.S. Immigration Politics. EUA: Oxford University Press, 2015. 272 p

O'FLAHERTY, Michael; FISCHER, John. Sexual Orientation, Gender Identity and International Human Rights Law: Contextualising the Yogyakarta Principles. Human Rights Law Review, vol. 8, n. 2, p. 222, 2008.

PRECIADO. Beatriz, Manifesto Contrassexual, trad. Maria Paula Gurgel Ribeiro, São Paulo: n-1 edições, p. 130, 2014.

ROCHA, Cássio Bruno Araújo. Um pequeno guia ao pensamento, aos conceitos e à obra de Judith Butler. Cadernos Pagu, n. 43, p. 507-516, jul./dez. 2014

SAIZ, Ignacio. Bracketing Sexuality: Human Rights and Sexual Orientation- A Decade of Development and Denial at the UN. SPW Working Papers, n. 2, nov. 2005.

SHAKHSARI, Sima. The queer time of death: Temporality, geopolitics, and refugee rights. Sexualities, vol. 17, n. 8, p. 998-1015, 2014.

SHUMAN, Amy.; BOHMER, Carol. Gender and Cultural Silences in the Political Asylum Process. Sexualities, vol. 17, n. 8, p. 947, 2014. 


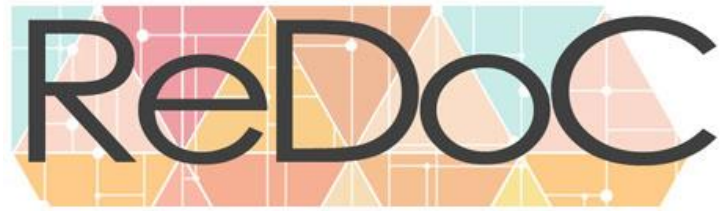

\section{Revista Docência e Cibercultura}

United Nations High Commissioner for Refugees (UNHCR), Protecting Persons with Diverse Sexual Orientations and Gender Identities: A Global Report on UNHCR's Efforts to Protect Lesbian, Gay, Bisexual, Transgender, and Intersex Asylum-Seekers and Refugees, December 2015, Disponível em: <http://www.refworld.org/docid/566140454.html> Acesso em 16 de Junho de 2018.

United Nations Human Rights - Office Of The High Commissioner. Born free and Equal Sexual Orientation and Gender Identity in International Human Rights Law. New York and Geneva, 2012.

Disponível em: https://www.ohchr.org/Documents/Publications/BornFreeAndEqualLowRes.pdf >. Acesso em 12 de junho de 2018.

United Nations Human Rights - Office Of The High Commissioner. Comments on the Practice of Phallometry in the Czech Republic to Determine the Credibility of Asylum Claims based on Persecution due to Sexual Orientation. Czech Republic: 2011. Disponível em: <http://www.refworld.org/docid/4daeb07b2.html>, Acesso em 14 junho de 2018. 